\title{
NARCISSISTIC PERSONALITY INVENTORY - POSSIBILITY OF APPLICATION ON A SERBIAN POPULATION
}

\author{
UDC 159.923.3.072.59
}

\author{
Milica Ristić ${ }^{1}$, Vladimir Hedrih ${ }^{2}$, Snežana Stojiljković ${ }^{2}$ \\ ${ }^{1}$ University of Niš, Pedagogical Faculty in Vranje, Serbia \\ ${ }^{2}$ University of Niš, Faculty of Philosophy, Department of Psychology, Niš, Serbia
}

\begin{abstract}
The main goal of this research was to investigate some of the psychometric properties of the Narcissistic Personality Inventory - reliability, applicability of a seven-factor structure and its construct validity for a sample of the Serbian population. For this purpose, a 40-item Narcissistic Personality Inventory - NPI and Rosenberg's Global Self-esteem scale were distributed via internet to 150 participants of both sexes, aged 19 - 56. Investigation of internal consistency of NPI was satisfactory - Cronbach alpha coefficient was 0.87. Also, the seven-factor structure of NPI found with the American sample did not correspond well to the factor structure found in the present study. The total scale score correlated with self-esteem, thereby supporting the validity of the scale.
\end{abstract}

Key words: narcissistic personality inventory, reliability, seven-factor structure, construct validity.

\section{INTRODUCTION}

The concept of narcissism relevant to the present paper is the concept in which narcissism is understood as a personality trait. Such an approach is essentially dimensional, i.e. there is an assumption that narcissism is manifested in various degrees even in the normal population. In cases where narcissism is manifested in a maladaptive and extreme way that meets the criteria of the DSM-IV classification, it is conceptualized as a clinical disorder (Kansi 2003). Otherwise, when it is manifested at a less extreme or sub-clinical level, certain forms of behavior can be considered a narcissistic personality trait.

Emmons (1984) states that there have been several attempts to construct an instrument that would measure individual differences in the manifestation of narcissism. Many of these instruments, like for example TAT and Rorschach, were projective. Ashby, Lee \& Duke (1979, according to Emmons 1987) developed the MMPI Narcissistic Personality Disorder

Received January 19, 2017 / Accepted June 16, 2017

Corresponding author: Milica Ristić

University of Niš, Pedagogical Faculty in Vranje, Partizanska 14, 17500 Vranje, Serbia

E-mail: milica.m82@gmail.com 
Scale (NPD) composed of 19 items from the MMPI. The given examples represent attempts to evaluate the pathological form of narcissism. However, studies performed to validate these scales were mostly conducted on student samples, and, consequently, the results were often misleading and difficult to interpret.

Until 1979, research studies dealing with the clinically relevant construct of narcissism were limited due to the lack of an appropriate instrument (Kansi 2003). Raskin and Hall (1979, according to Kansi 2003) developed the Narcissistic Personality Inventory (NPI) in order to measure narcissism as a personality trait in a normal population. This inventory is theoretically grounded in a definition of narcissism that relies on the diagnostic criteria of the narcissistic personality disorder specified in the Diagnostic and Statistical Manual of Mental Disorders (DSM-III, American Psychiatric Association 1980). These criteria include the following:

- grandiose sense of self-importance and uniqueness;

- preoccupation with fantasies of unlimited success, power, brilliance, beauty, or ideal love;

- exhibitionism;

- cold indifference or pronounced feelings of rage, inferiority, shame, humiliation or emptiness, as well as the inability to accept criticism, and indifference to others;

- at least two of the following characteristics of interpersonal relations disorder:

- feelings of entitlement: expecting special favors without taking into consideration the possibility of reciprocal responsibility;

- exploitativeness;

- relationships characterized by the alternation between two extremes: idealization or devaluation;

- lack of empathy.

However, although it is based on the personality disorder criteria, according to Pincus et al. (2009) this inventory serves as a measurement of normal and adaptive narcissism. The authors arrived at such a conclusion, first of all, based on the review of results of numerous studies that found a positive correlation of a construct measured in such a way and, for example, motivation for achievement and self-esteem, as well as with other measures connected to wellbeing. Starting from the assumption that there is a continuum between abnormality and normality, Raskin and Hall (1981) consider that behaviors described by these criteria represent extreme forms that are present to a smaller degree even in normal individuals. Based on a series of studies, the authors came up with an instrument consisting of 54 items. Each item included of a pair of statements, where choosing one of the statements marked the presence, while choosing the other marked the absence of a narcissistic personality trait.

Applying factor analysis to the Narcissistic Personality Inventory, Emmons (1984) was able to extract four factors: Exploitativeness/Entitlement, Leadership/Authority, Superiority/ Arrogance, and Self-absorption/Self-admiration. All factors, except for Exploitativeness/ Entitlement, positively correlated with self-esteem. Raskin and Terry (1988) performed another factor analysis on the instrument. Namely, based on the analysis of the obtained results they concluded that, after removing 14 items, the most acceptable solution contained 7 factors, which were as follows: Authority, Exhibitionism, Superiority, Entitlement, Exploitativeness, Self-sufficiency, and Vanity. This way the authors created one of the most 
commonly used instruments for the evaluation of narcissism as a personality trait - the Narcissistic Personality Inventory composed of 40 items.

However, there is still disagreement among authors concerning the number of factors that best describe the narcissistic personality. Ackerman et al. (2010) note that, although NPI is a widely used measure of narcissism, its factorial structure and the most adequate number of factors are still a matter of debate. For instance, as mentioned above, Emmons (1984) stresses four factors. Based on the analysis of their research, Kubarych, Deary, and Austin (2004) offer two solutions. One solution involves a two-factor-structure, where one is linked to power and the other with exhibitionism. The three-factor-solution proposed in Kubarych, Deary, and Austin (2004) includes factors linked to power, exhibitionism, and uniqueness. Still, owing to low saturation, several items from both models have been rejected. The authors concluded that the NPI represents a measure of general narcissism with two or three connected factors that refer to power, exhibitionism, and self-admiration. Results of exploratory factor analysis performed by Barelds and Dijkstra (2010) go in favor of the existence of either one factor of general narcissism or a two-factor solution (Authority/Power and Self-admiration). Corry et al. used factor analysis to extract two factors comprised of 23 items, which were connected to the content of leadership/authority and exhibitionism/entitlement.

Although the issue of factor-structure of the Narcissistic Personality Inventory remains unresolved, results of a study conducted by Buss and Chiodo (1991) offer significant support for the application of this inventory on a sub-clinical population. Bearing in mind that, although constructed as a measure of narcissism on a normal population, the inventory is still based on diagnostic criteria of the DSM-III classification, the results obtained by Buss and Chiodo are highly relevant as they offer the basis for the preservation of the link between diagnostic classification and psychopathology of everyday behavior. Namely, the main goal of these authors was to identify behaviors central to the category of narcissism in everyday life. The agreement between experts and laypeople concerning these characteristics enabled the authors to rely on laypeople's understanding in determining the most typical narcissistic acts in everyday life. The overview of characteristics offered by laypeople reveals themes most commonly recognized as a manifestation of narcissism. These include the following: egocentrism (e.g. he was talking about himself without listening to anyone else), exhibitionism (e.g. exposing one's body while others are watching), self-admiration (e.g. a man explaining that the best way to find a girlfriend is to be like him) and grandiosity (e.g. saying without hesitation that he is handsome and smart). The authors managed to identify many of these components in the description of DSM-III classification of the narcissistic personality disorder.

Constructing an adequate inventory for exploring the salience of narcissistic personality traits on a sub-clinical population can be significant for multiple reasons. One of them stems from the research results showing the link between narcissism and strategies of preservation and improvement of the self-image (Raskin, Novacek and Hogan 1991; Bushman and Baumeister 1998). These strategies are often maladaptive and can be threatening to both the individual and the people in their surroundings. In addition, narcissism has also been linked to aggression (Bushman and Baumeister 1998) and lack of empathy (Watson, Grisham, Trotter and Biderman 1984), which can have a significant influence on an individual's interpersonal relationships. Moreover, understanding the concept of narcissism can significantly help in the study of the issues of identity and self-respect. 
The main problem of the present research can be presented through the following two questions: "Is NPI a sufficiently reliable and suitable measurement of narcissism for the Serbian population?", and "Is the seven-factor-solution, proposed by the authors of this inventory, applicable to the Serbian population?"

\subsection{Research goals}

In order to check the psychometrics properties of the Serbian version of NPI (Narcissistic Personality Inventory, Raskin and Terry 1988) on a sample extracted from the Serbian population, the following three goals have been proposed:

1. To determine whether the reliability of the inventory used with the sample from Serbia reached a satisfactory level;

2. To check whether the seven-factor-structure obtained from the American sample matches the factor structure obtained from the Serbian sample;

3. To investigate the construct validity of the inventory by checking the correlation with self-esteem.

Since numerous research studies have identified a positive link between narcissism and self-esteem (e.g. Raskin, Novacek \& Hogan 1991; Rhodewalt and Morf 1995; Emmons 1984), the present research will also rely on this correlation as an indicator of external validity of the Serbian version of the inventory on the current sample.

\section{METHOD}

\subsection{Sample and procedure}

The 40-NPI scale was adapted from English to Serbian through a back-translation procedure. Namely, the scale was first translated into Serbian and then the obtained version in Serbian was translated back into English. The comparison of the two English versions showed a satisfactory match.

The data were collected online from a convenient sample of participants. The sample consisted of 150 participants of both sexes, with an age range between 19 and 56 (Tables 1 and 2).

Table 1 Gender structure of the sample

\begin{tabular}{lrc}
\hline Gender & $\mathrm{N}$ & $\%$ \\
\hline Male & 52 & $34,7 \%$ \\
Female & 98 & $65,3 \%$ \\
\hline Total & 150 & $100,0 \%$ \\
\hline
\end{tabular}

Table 2 Age structure of the sample

\begin{tabular}{lrr}
\hline Age & $\mathrm{N}$ & \multicolumn{1}{c}{$\%$} \\
\hline $19-29$ & 100 & $66,6 \%$ \\
$30-42$ & 39 & $26,0 \%$ \\
$43-56$ & 11 & $7,3 \%$ \\
\hline Total & 150 & $100,0 \%$ \\
\hline
\end{tabular}




\subsection{Instruments}

Narcissistic Personality Inventory - NPI (Raskin and Terry 1988) consists of 40 dichotomous items, and the participants provide their answers through a forced-choice procedure by opting for one of the two statements that the item contains. Additionally, one statement signals the presence, whereas the other one signals the absence of a narcissistic trait. Examples of NPI items, i.e. the statements it contains and between which participants need to choose are the following: "Essentially I am a modest person" or "Modesty does not describe me," "If I ruled the world it would be a better place" or "The thought of ruling the world scares me."

Rosenberg's Self-Esteem Scale (Rosenberg 1965). The scale was initially developed for the measurement of global self-esteem and self-acceptance of adolescents and it is generally considered a standard against which other measures of self-esteem are compared. The scale consists of 10 Likert-type items that have high face validity.

\section{RESULTS}

\subsection{Reliability of the Narcissistic Personality Inventory}

Assessment of the internal consistency of NPI on the current sample showed that it was satisfactory - Cronbach's alpha was measured at .87. Inter-item correlations ranged between .23 and .67. Individual item correlations with the overall score on the scale ranged from .08 to .58 .

\subsection{Assessment of the seven-factor structure of the Narcissistic Personality Inventory}

In order to assess the seven-factor structure of the inventory for the Serbian sample, a principal components analysis with the promax rotation was performed. This method was chosen in line with the assumption that the factors are interrelated, as well as that the narcissistic trait is defined through their combination. Exploratory factor analysis of the principal components was also chosen with the intent to use the same procedures used in the original research by Raskin and Terry (1988) as much as possible. The minimal factor loading of .35 was also chosen based on the criteria from the afore mentioned research.

The seven factors obtained from the Serbian sample account for the total of $46 \%$ of variance. The overview of factor structure and item saturation with each of the factors for the Serbian sample is shown in Table 3.

For all the items, except for item 14 ("I insist on getting the respect I deserve") have a saturation larger than .35. In addition, item 11 ("I am assertive") is saturated, almost equally, by two factors, so these two items will not be taken into account in the discussion of the results.

In order to facilitate the comparison, Table 4 gives an overview of factor structure and NPI item loadings for the Serbian sample (henceforth S-NPI), and Raskin and Terry 's sample (1988, henceforth RT-NPI). 
Table 3 Pattern matrix after rotation - factor structure and NPI item saturations for the Serbian sample

\begin{tabular}{|c|c|c|c|c|c|c|c|}
\hline \multirow[b]{2}{*}{ Items } & \multicolumn{7}{|c|}{ Factor loadings } \\
\hline & 1 & 2 & 3 & 4 & 5 & 6 & 7 \\
\hline NPI1 & .23 & .03 & -.03 & -.04 & -.02 & .34 & .51 \\
\hline NPI2 & .08 & .40 & -.16 & .33 & .25 & .21 & -.12 \\
\hline NPI3 & -.21 & -.15 & .07 & .06 & .11 & .83 & .05 \\
\hline NPI4 & .07 & .56 & -.10 & .40 & .00 & -.05 & .15 \\
\hline NPI5 & .42 & .12 & -.12 & .08 & -.09 & -.06 & .05 \\
\hline NPI6 & .47 & .18 & -.05 & -.21 & -.05 & -.07 & .00 \\
\hline NPI7 & .18 & .20 & .12 & .03 & .03 & .43 & .03 \\
\hline NPI8 & .43 & -.05 & .06 & .13 & .08 & .26 & -.26 \\
\hline NPI9 & .01 & -.01 & .81 & -.14 & -.03 & .06 & -.10 \\
\hline NPI10 & .72 & -.26 & -.02 & .20 & -.01 & .04 & .26 \\
\hline NPI11 & -.15 & -.19 & .45 & .46 & .14 & .04 & .15 \\
\hline NPI12 & .68 & -.12 & -.01 & -.08 & -.03 & -.07 & .18 \\
\hline NPI13 & .04 & -.08 & -.01 & .43 & .08 & .04 & .01 \\
\hline NPI14 & .19 & -.03 & .23 & -.20 & .01 & -.01 & -.55 \\
\hline NPI15 & .02 & .51 & .22 & -.12 & -.07 & .17 & -.03 \\
\hline NPI16 & .06 & .05 & .23 & .04 & -.20 & -.12 & .37 \\
\hline NPI17 & .15 & -.04 & -.11 & .54 & -.05 & .24 & -.10 \\
\hline NPI18 & .03 & .00 & .34 & -.01 & .51 & -.22 & -.11 \\
\hline NPI19 & -.02 & .44 & .28 & -.25 & -.17 & .15 & .17 \\
\hline NPI20 & -.24 & .61 & -.08 & .13 & .14 & -.14 & .07 \\
\hline NPI21 & .08 & .12 & -.07 & .66 & -.02 & -.09 & .17 \\
\hline NPI22 & -.10 & .04 & .45 & .31 & -.33 & .01 & .07 \\
\hline NPI23 & -.13 & .22 & .28 & .02 & .23 & .09 & .37 \\
\hline NPI24 & -.04 & .09 & -.12 & .03 & .75 & -.04 & -.06 \\
\hline NPI25 & .19 & -.12 & -.01 & .02 & .59 & .21 & .00 \\
\hline NPI26 & -.23 & .67 & -.02 & .31 & .05 & -.07 & -.01 \\
\hline NPI27 & .65 & .09 & .07 & -.12 & .24 & -.16 & -.23 \\
\hline NPI28 & .18 & .66 & -.24 & -.16 & -.15 & -.18 & .01 \\
\hline NPI29 & -.15 & .73 & .11 & -.14 & .05 & .03 & .01 \\
\hline NPI30 & .25 & .43 & -.09 & .14 & -.06 & .32 & .07 \\
\hline NPI31 & .06 & .09 & .46 & .28 & -.30 & .03 & -.35 \\
\hline NPI32 & .49 & .03 & .04 & .08 & -.09 & -.24 & .39 \\
\hline NPI33 & .81 & -.24 & -.07 & .11 & .00 & -.02 & -.02 \\
\hline NPI34 & .39 & .14 & .26 & .12 & .14 & -.15 & .06 \\
\hline NPI35 & .26 & .02 & .14 & -.12 & .08 & .30 & .45 \\
\hline NPI36 & .63 & -.03 & .02 & .15 & -.04 & .06 & -.15 \\
\hline NPI37 & -.12 & .03 & .04 & .08 & .67 & .22 & .06 \\
\hline NPI38 & .17 & .36 & .08 & -.30 & .17 & -.18 & -.08 \\
\hline NPI39 & .33 & .03 & .13 & .35 & .10 & -.35 & .05 \\
\hline NPI40 & -.04 & -.09 & .74 & -.04 & .13 & .06 & .11 \\
\hline
\end{tabular}


Table 4 Overview of factor structure of the present research (S-NPI) and Raskin and Terry's factor structure, and factorial loading of items

\begin{tabular}{|c|c|c|c|}
\hline S-NPI & loading & RT-NPI & loading \\
\hline Factor 1 & & Factor 1. Authority & \\
\hline 5. & .42 & 1. & .66 \\
\hline 6. & .47 & 8. & .67 \\
\hline 8. & .43 & 10. & .83 \\
\hline 10. & .72 & 11. & .56 \\
\hline 12. & 68 & 12. & .56 \\
\hline 27. & .65 & 32. & .66 \\
\hline 32. & .49 & 33. & .83 \\
\hline 33. & .81 & 36. & .35 \\
\hline 34. & .39 & & \\
\hline 36. & 63 & & \\
\hline Factor 2. & & Factor 4. Exhibitionism & \\
\hline 2. & .40 & 2. & .69 \\
\hline 4. & .56 & 3. & .48 \\
\hline 15. & .51 & 7. & .49 \\
\hline 19. & .44 & 20. & .71 \\
\hline 20. & 61 & 28. & .35 \\
\hline 26. & .67 & 30. & .46 \\
\hline 28. & 66 & 38. & .51 \\
\hline 29. & .73 & & \\
\hline 30. & 43 & & \\
\hline 38. & .36 & & \\
\hline Factor 3. & & Factor 6. Vanity & \\
\hline 9. & .81 & 15. & .76 \\
\hline 22. & .4 & 19. & .87 \\
\hline 31. & .46 & 29. & .79 \\
\hline 40. & .74 & & \\
\hline Factor 4. & & Factor 3. Superiority & \\
\hline 13. & .43 & 4. & .69 \\
\hline 17. & .54 & 9. & .64 \\
\hline 21. & .66 & 26. & .67 \\
\hline \multirow[t]{2}{*}{39.} & .35 & 37. & .57 \\
\hline & & & .69 \\
\hline Factor 5. & & Factor 2. Self-Sufficiency & \\
\hline 18. & .51 & 17. & .59 \\
\hline 24. & .75 & 21. & .46 \\
\hline 25. & .59 & 22. & .61 \\
\hline \multirow[t]{3}{*}{37.} & 67 & 31. & .46 \\
\hline & & 34. & .43 \\
\hline & & 39. & .57 \\
\hline Factor 6. & & Factor 7. Entitlement & \\
\hline 3. & .83 & 5. & .35 \\
\hline \multirow[t]{5}{*}{7.} & 43 & 14. & .45 \\
\hline & & 18. & .53 \\
\hline & & 24. & .68 \\
\hline & & 25. & .70 \\
\hline & & 27. & .49 \\
\hline Factor 7. & & Factor 5. Exploitativeness & \\
\hline 1. & .51 & 6. & .62 \\
\hline 16 & .37 & 13. & .66 \\
\hline 23. & .37 & 16. & .71 \\
\hline \multirow[t]{2}{*}{35.} & .45 & 23. & .43 \\
\hline & & 35. & .69 \\
\hline
\end{tabular}


The first S-NPI factor consists of 10 items, where 6 items have similar saturations as the first RT-NPI factor of Authority. In general, it can be concluded that the content of the first factor reflects the content of the Authority factor, although saturations of several Serbian items are lower compared to the American ones. Still, there is a high statistically significant connection between the first S-NPI factor and the first RT-NPI factor of Authority $(.89, \mathrm{p}<0.01)$.

The second S-NPI factor also contained 10 items, half of which had similar saturations as the fourth RT-NPI factor of Exhibitionism. However, the content of the second S-NPI factor includes the entire sixth RT-NPI factor of Vanity. Saturations of these items with the second S-NPI factor are lower, except for item 23, than their saturation with the factor Vanity for the RT-NPI sample. The correlation between the second S-NPI factor and Fourth RT-NPI factor is positive and statistically significant $(.80, \mathrm{p}<0.01)$, as was the correlation with the sixth RTNPI factor $(.79, \mathrm{p}<0.01)$.

The third S-NPI factor consists of four items that stress uniqueness and independence. Item saturations only partially correspond to the content of the third RT-NPI factor of Superiority. In other words, the two items have similar saturations as the factor of Superiority, while the meanings of two items from the RT-NPI are included in the second factor of Self-sufficiency. Still, the correlation between the third S-NPI factor and the factor of Superiority is positive and statistically significant $(r=.70, \mathrm{p}<.01)$.

The fourth S-NPI factor includes three items. Overall, it can be concluded that the content of this factor is similar to the content of the second RT-NPI factor of Selfsufficiency, where items in the fourth S-NPI factor stress capabilities and independence rather than complete independence from others. The correlation between the two factors is positive and statistically significant $(\mathrm{r}=.77, \mathrm{p}<.01)$.

The fifth S-NPI factor includes four items that point to standing out before others and entitlement. Saturations with these three items are similar to those from the seventh RTNPI factor of entitlement. Additionally, there is a positive, statistically significant correlation between these two factors $(r=.82, \mathrm{p}<.01)$.

The sixth S-NPI factor consists of two items. Bearing in mind that the theoretical minimum for interpretation, i.e. the naming of factors, for which we have opted in this paper is the presence of at least three items with the factorial saturation of .35 and/or more, this factor will not be taken into consideration.

The seventh factor of S-NPI contains four items that foreground the ability to influence and possibility to manipulate others. Three of these items correspond with the content of the fifth RT-NPI factor of exploitativeness, although the saturations of these items with the seventh factor are lower than their saturations with the RT-NPI factor. The link between these two factors is positive and statistically significant $(\mathrm{r}=.80, \mathrm{p}<0.01)$.

In order to check the agreement between the two factorial solutions (S-NPI and RT-NPI), Tucker's congruence coefficient was taken as a measure of agreement. The results showed that the highest correspondence was present between the first S-NPI and first RT-NPI factor (Tucker's congruence coefficient measured at .68). However, this correspondence is insufficient for factors to be considered similar. Bearing in mind that none of the coefficients are greater than 0.90 , it can be concluded that the factorial structures of S-NPI and RT-NPI do not match.

\subsection{Correlation between narcissism and self-esteem}

The results show that there is a positive and statistically significant correlation between narcissism and self-esteem $(r=.39 ; \mathrm{p}<0.1)$. Pearson correlation coefficient was calculated. 


\section{DISCUSSION AND CONCLUSION}

The present paper explored the basic psychometric characteristics of the Narcissistic Personality Inventory - reliability, adequacy of the seven-factor structure for the Serbian sample, as well as the correlation between narcissism and self-esteem, which represents one of the ways for assessing construct validity. The reliability of the inventory for the investigation of narcissism on a Serbian sample, determined based on the measurements of internal consistency, was satisfactory and in line with the standards of use of psychological inventories. Based on the identified statistically significant positive correlation with the external criterion, it can be concluded that the construct validity of the scale is also satisfactory.

Concerning the assessment of the factor structure through the method used in the paper, it can be concluded that a seven-factor solution is not suitable for the Serbian sample, which is evidenced by the size of Tucker's congruency coefficient. Still, we must not overlook the results with similar content and saturations of certain factors with both samples, as well as the presence of relatively high and statistically significant correlations between these factors.

When interpreting the obtained results, characteristics of both samples need to be taken into consideration - first of all, their size and structure. The American sample included 1,018 undergraduate students from two universities, with an age range from 17 to 49 , while the Serbian sample included 150 participants, where the data were collected online, and an age range between 19 and 65. Therefore, the American sample was a lot larger and more homogeneous compared to the Serbian sample.

However, even with the original factor structure presented by Raskin and Terry (1988), which was obtained from an American sample, it can be concluded that the content of certain items is not in line with the theoretical specification of the factors. For instance, some of the items within the entitlement factor are linked to the concept of power. Yet that is not in line with the diagnostic criteria according to which entitlement refers to the expectation of special favors without taking into consideration the possibility of reciprocal responsibilities. Also, items from the self-sufficiency scale seem to be reflecting superiority, authority and entitlement.

Interpretation of factor structure of the NPI (Raskin and Hall 1979; following Corry Davis Merrit, Mrug and Pamp 2008) is blurred by the contradictory results obtained from various studies whose goal was to determine the factorial structure. Therefore, the latent structure of the NPI still remains an open question. Additionally, the cross-cultural stability of the used measure of narcissism is also worth mentioning. Based on the results obtained in the present study, it is clear that the factors meet the condition of congenericness, i.e. all the items measure the same construct. However, differences are identified only when additional components are analyzed and one of the causes for these differences may be attributed to cross-cultural differences (e.g. emics and etics). For instance, results obtained from a study that was conducted in order to check the factorial structure of NPI on a Swedish sample (Kansi 2003) were also not in line with the seven-factor structure of NPI obtained from the American sample. That study obtained a partial overlap with the Emons' four-factor structure, and the author attributed such findings to cross-cultural differences. Namely, the traits of entitlement, assertiveness, and immodesty - aspects often understood as positive in America, are not necessarily understood as such in Sweden. In turn, the disposition of the Swedish sample to demonstrate these feelings can be reduced. 
Different understandings of the concept of narcissism are linked to specific cultures, which can, in turn, be used to at least partially account for the identified differences. Following the afore mentioned research conducted by Buss and Chiodo (1991), it would be useful to investigate the very content of the concept of narcissism in everyday life of our culture, as well as the overlap between laypeople's understanding of this concept with the understanding of experts.

Another important question concerns the manner in which narcissistic traits are manifested in the sub-clinical population. Dynamically orientated researchers (e.g. Kernberg 1975, 1986; Kohut 1977; according to Wink 1991) have put forward assumptions about the existence of two forms of narcissism - open and concealed. With open narcissism, the narcissistic feeling of grandeur leads to direct expressions of exhibitionism, feelings of personal importance and superiority, as well as to the obsession with gaining the attention and admiration of others. This form of narcissism can be identified in the DSM-III criterion. NPI, which is the most commonly applied instrument for the measurement of narcissism (according to Wink 1991), measures this form of narcissism. The other form of narcissism is concealed narcissism, characterized by subconscious feelings of grandeur, and an open display of lack of self-confidence and initiative, unspecified feelings of depression, as well as the lack of work drive (the so-called narcissistic deficit). Still, such individuals have certain traits that are shared with individuals that have the open form of narcissism. First of all, it is the tendency to take advantage of others, and the feeling of entitlement (Wink 1991). NPI was developed as a measurement of open narcissism based on the DSMIII classification - it is unclear whether narcissism is also manifested as open and concealed narcissism in the normal population, or whether it is more probable that narcissism will assume the concealed form, which is more difficult to recognize in a sub-clinical sample.

What offers a lot of space for further research is the structure of NPI itself. As argued by Corry et al. (2008), it is unclear whether the forced-choice design is the best solution. Perhaps a Likert-type scale would facilitate interpretation and yield a more complex measurement that would give the participants more leeway to express their trait or a lack thereof to a certain extent. Moreover, such an approach would provide a clearer difference between maladaptive and adaptive aspects of narcissism. Additionally, the DSM-III classification on which the inventory is based dates from 1980. The question that remains open is whether the construction of NPI based on the current DSM V classification would require drastic changes, even if NPI is understood as the measurement of normal narcissism. The remark offered by Jayson (2013) that the latest handbook contains diagnostic criteria that have been revised to a great extent, where in some cases diagnostic definitions are expanded, and in others narrowed down, is also in accordance with this line of reasoning.

In conclusion, discussion of the present results offers a guideline for future research. Firstly, the present research needs to be repeated - on the one hand because it is dealing with a concept that is insufficiently explored in our environment, and on the other because it needs to be repeated on a larger sample in order to allow for possible generalizations. In addition, suggestions for future research should be directed towards the use of some other rotation procedures and finding adequate latent solutions.

Acknowledgement: Prepared as a part of the project 179002, supported by the Ministry of Education and Science of the Republic of Serbia. 


\section{REFERENCES}

Ackerman, R. A., E. A. Witt, M. B. Donnellan, K. H. Trzesniewski, R. W. Robins, and D. A. Kashy. "What does the Narcissistic Personality Inventory Really Measure?” Assessment (2010). 1073191110382845.

American Psychiatric Association. Diagnostic and Statistical manual of Mental Disorders, 3rd ed. Washington, DC, 1980.

Barelds, D. P. H., and P. Dijkstra. "Narcissistic Personality Inventory: Structure of the Adapted Dutch Version". Scandinavian Journal of Psychology 51, 2 (2010): 132-138.

Bushman, J. B., and F. R. Baumeister. "Threatened Egotism, Narcissism, Self-esteem, and Direct and Displaced Aggression: Does Self-love or Self-hate Lead to Violence?" Journal of Personality and Social Psychology 75, 1 (1998): 219-229.

Buss, D. M., \& L. M. Chiodo. "Narcissistic Acts in Everyday Life”. Journal of Personality 59 (1991): 179-215.

Corry, N., R. Davis Merritt, S. Mrug, and B. Pamp. "The Factor Structure of the Narcissistic Personality Inventory". Journal of Personality Assessment 90, 6 (2008): 593-600.

Emmons, R. "Factor Analysis and Construct Validity of the Narcissistic Personality Inventory". Journal of Personality Assesment 48, 3 (1984): 291-300.

Emmons, R. A. "Narcissism: Theory and Measurement”. Journal of Personality and Social Psychology 52, 1 (1987): 11.

Jayson, S. "Books Blast New Version of Psychiatry's Bible, the DSM". USA Today. Accessed May $12^{\text {th }} 2013$. Available at: http://www.usatoday.com/story/news/nation/2013/05/12/dsm-psychiatry-mental-disorders/2150819/

Kansi, J. "The Narcissistic Personality Inventory: Applicability in a Swedish Population Sample". Scandinavian Journal of Psychology 44 (2003): 441-448.

Kubarych, S. T., J. I. Deary, and J. A. Austin. "The Narcissistic Personality Inventory: Factor Structure in a Non-clinical Sample". Personality and Individual Differences 36 (2004): 857-872.

Morf, C. C., and F. Rhodewalt. Unraveling the Paradoxes of Narcissism: A Dynamic Self-regulatory Processing Model". Psychological Inquiry 12, 4 (2001): 17-196.

Pincus, A. L., E. B. Ansell, C. A. Pimentel, N. M. Cain, A. G. Wright, and K. N. Levy. "Initial Construction and Validation of the Pathological Narcissism Inventory". Psychological Assessment 21, 3 (2009): 365.

Raskin, R., and S. C. Hall. "The Narcissistic Personality Inventory: Alternate form Reliability and Further Evidence of Construct Validity”. Journal of Personality Assessment 45, 2 (1981): 159-162.

Raskin, R., J., Novacek, and R. Hogan. "Narcissism, Self-esteem, and Defensive Self-enhancement". Journal of Personality 59, 1 (1991): 19-38.

Raskin, R., and H. Terry. "A Principal-components Analysis of the Narcissistic Personality Inventory and Further Evidence of its Construct Validity". Journal of Personality and Social Psychology 54, 5 (1988): 890-902.

Rhodewalt, F., and C. C. Morf. "Self and Interpersonal Correlates of the Narcissistic Personality Inventory: A Review and New Findings". Journal of Research in Personality 29, 1 (1995): 1-23.

Rosenberg, M. Society and the Adolescent Self-image. New York: Princeton University Press, 1965.

Watson, P. J., O. S. Grisham, V. M. Trotter, and D. M. Biderman. Narcissism and Empathy: Validity Evidence for the Narcissistic Personality Inventory". Journal of Personality Assessment 48, 3 (1984): 301-305.

Wink, P. “Two Faces of Narcissism”. Journal of Personality and Social Psychology 61, 4 (1991): 590-597.

\section{INVENTAR NARCISTIČNE LIČNOSTI - MOGUĆNOST PRIMENE NA SRPSKOJ POPULACIJI}

Glavni cilj ovog rada je ispitivanje psihometrijskih svojstava Inventara narcistične ličnosti njegove pouzdanosti, primenljivosti sedmofaktorske structure $i$ konstruktne validnosti na srpskom uzorku. U ovu svrhu četrdesetoajtemski Inventar narcistične ličnosti (NPI) I Rosenbergova skala globalnog samopoištovanja zadate su putem internet uzorku od 150 učesnika, oba pola, starosti od 19 do 56 godina. Ispitivanje interne konzistencije NPI pokazalo je zadovoljavajuću pouzdanost ovog testa na ispitivanom uzorku. - Kronbahova alfa bila je 0,87. Međutim, sedmofaktorska struktura koja je dobijena na američkom uzorku nije odgovarala faktorskoj strukturi koja je dobijena u ovoj studiji. Ukupni skor skale korelirao je sa samopoštovanjem, što govori u prilog eksternoj validnosti NPIa.

Ključne reči: inventar narcistične ličnosti, pouzdanost, sedmofaktorska struktura, konstruktna validnost. 